\title{
História do percurso da sociologia e da antropologia na área da infância
}

\begin{abstract}
Adriana Friedmann é educadora, doutora em Antropologia e Mestre em Metodología do Ensino. Coordena o curso de Pós-graduação em "Educação Lúdica em contextos escolares, não formais e corporativos" do ISE Vera Cruz. É cofundadora da Aliança pela Infância e consultora de várias fundações nacionais e internacionais que atuam na área da Infância. É autora de vários livros sobre o brincar e a infância.
\end{abstract}

Contato: nepsid@globo.com

\section{Resumo}

0 presente artigo pretende contribuir para situar o leitor a respeito da história e do estado da arte dos estudos, teorias e autores relevantes na área de Ciências Sociais - Sociologia e Antropologia - no âmbito da Infância. 0 artigo apresenta as principais ideias que norteiam esses estudos e aponta para a importância de uma interlocução com as áreas de Psicologia do Desenvolvimento e Educação. Alguns caminhos metodológicos utilizados por antropólogos são citados, assim como referências bibliográficas essenciais.

Palavras-chave: infância; crianças; antropologia; pesquisas, culturas infantis.

\section{Abstract}

This paper aims to situate the reader about the history and the state of the studies, theories and relevant authors in the area of Social Sciences - Sociology and Anthropology - in the field of Childhood. The article presents the main ideas that guide these studies and points to the importance of a dialogue with the areas of Developmental Psychology and Education. Some methodological approaches used by anthropologists are cited, and basic references.

Keywords: childhood, children, anthropology, research, children's cultures. 
Os estudos sobre a infância vêm crescendo nas últimas décadas e impondo transformações importantes em suas disciplinas de origem, como a Sociologia, a Antropologia, a História e a Filosofia. Aqui serão enfatizados os surgimentos da Antropologia e da Sociologia da Infância, apontando para a importância da interlocução entre estas áreas e o pensamento educacional. Para tanto, será apresentado um percurso histórico do desenvolvimento destes campos de estudos, seguido de um levantamento de suas principais metodologias, enfoques e autores.

As primeiras referências às crianças na Antropologia da Infância aparecem em finais do século XIX, entre os evolucionistas Tylor (1871) e Spencer (1882), que tentavam estabelecer padrões para os estágios de desenvolvimento da espécie humana, discurso que irá atravessar cerca de 100 anos e migrar para a Pedagogia, a Psicologia, a Assistência Social, a Medicina e o Direito. Esses fundamentos influenciaram a teoria sobre o desenvolvimento infantil de Piaget, a partir dos anos 20, assim como conceitos de socialização infantil.

Margaret Mead foi, na Antropologia, a primeira a romper com esses pressupostos, no final da década de 1920, trazendo os estudos sobre o universo infantil para a Antropologia e alertando sobre a influência da cultura no seu processo de crescimento, contrapondo-se às teorias que explicavam o comportamento infantil como sendo biologicamente determinado. Mead recolheu e formatou o maior conjunto de dados etnográficos sistemáticos que existe sobre crianças em sociedades não ocidentais (3200 desenhos infantis), defendendo a importância de conhecer suas vidas para entender o que acontece na adolescência. Mead defendia que as crianças não nascem "balinesas", por exemplo, mas tornam-se "balinesas" por meio de um processo educacional que está imerso em uma cultura, não dependendo exclusivamente das etapas de maturação biológica do indivíduo.

Mead foi influenciada por Franz Boas (1925) e por Ruth Benedict, fazendo uso de métodos de pesquisa específicos da Antropologia (qualitativos e comparativos): observação continuada e participação nos seus cotidianos, diferentemente de testes, observações em contextos isolados ou elaboração de estatísticas. Os métodos de Mead - pioneiros no uso da fotografia e do filme são reconhecidos como válidos até hoje. As imagens foram por ela consideradas extremamente importantes pelos inúmeros detalhes que mostram, impossíveis de serem descritos com palavras. 
Mead teve muita influência da Psicologia. A sua grande contribuição foi a inclusão da cultura como variante de análise. Seu trabalho pioneiro foi limitado por não ter outros dados etnográficos e outros interlocutores para comparar os dados obtidos. Nos anos 1970, ela aponta, em artigo, o desinteresse da Antropologia pelos assuntos da infância, ao falar das potencialidades da atividade lúdica infantil e as lacunas nesta área, concordando com as ideias expostas por Ariès (1962) de que as crianças são consideradas seres sociais "incompletos".

Em meados do século XX, um grupo de antropólogos, interessou-se pelos estudos da organização familiar e do grupo doméstico: Meyer Fortes (1958-1971), Jack Goody (1958-1971) e Evans Pritchard (1956). Eles defendiam que o indivíduo não se desenvolve só física ou biologicamente, mas que esse processo de crescimento está vinculado ao sistema social do grupo ao qual pertence, concretizado por meio de um processo educacional próprio da sua cultura e do alargamento progressivo das relações sociais que estabelece no decorrer da sua vida.

Mas as crianças continuam a ocupar um lugar secundário e passivo nas análises feitas para ilustrar outros temas. Pode-se citar, como exceção, Evans Pritchard no seu estudo dos Nuer, mostrando que as crianças são potenciais reveladoras de algo que conviria investigar.

A partir da década de 1970, a Antropologia estabelece relações interdisciplinares com outras áreas das Ciências Humanas: História, Sociologia, Assistência Social.

A obra de Phillipe Ariès (1962) foi um marco no rumo dos estudos sobre a Infância: ele mostra que a Infância é uma construção histórica que emerge em um dado momento e em um dado grupo social. Na Idade Média, pelo fato de as crianças não serem representadas nas iconografias, não existiria um conceito objetivo para a Infância. A criança era representada como um adulto em miniatura. Ariès, De Mause (1976) e outros historiadores mostraram que o conceito de infância eclode, na modernidade europeia, com as ideias de Rousseau. A tese de Ariès é polêmica, mas importante para avançar na reflexão da existência de várias infâncias em oposição à ideia de uma infância única para todos os povos e todas as épocas. Essa tese é uma das bases paradigmáticas dos recentes estudos sociais sobre a infância.

Charlotte Hardman (1973) no seu artigo Can there be an Anthropology of Children?, tenta, pela primeira vez, sistematizar 
as tendências e contribuições na área; este artigo constitui uma referência imprescindível. Ela começa por citar a obra de lona e Peter Opie, Children Games in Street and Playground, em que os autores mostram que as tradições infantis circulam de uma criança para a outra, fora da influência do círculo familiar. Eles acreditam que os adultos sabem pouco sobre as crianças e que, de uma geração à outra, essa cultura da consciência de si continua a não ser noticiada. Hardman pergunta-se: como podemos interpretar os jogos infantis e sua tradição oral? Como as crianças podem ser ensinadas e como classificam ou pensam seu mundo? Que diferença a idade faz?

Como pode ser desenvolvida uma abordagem antropológica das crianças? Como pode diferenciar-se de abordagens teóricas que se preocupam com as crianças no sentido do que refletem do comportamento ou pensamento adulto? Que termos analíticos podem ser usados?

Para a autora, a grande diferença da Antropologia das crianças com relação a outras disciplinas é que, em vez de enfatizar o diacrônico, Hardman quer enfatizar o sincrônico: "como se pode estudar algo que ainda não é, salvo em termos do seu desenvolvimento?"

A proposta de Hardman (2001) é uma abordagem das crianças como pessoas a serem estudadas nos seus próprios direitos: ela procura descobrir se há, na infância, um mundo autônomo e autorregulado que não necessariamente reflete o desenvolvimento infantil da cultura adulta.

\footnotetext{
Se concebermos a sociedade como um grupo de entrelaçamentos, círculos sobrepostos, que, como um todo, forma um estoque de crenças, valores, interações sociais, então a infância (por exemplo, as crianças de quatro a onze anos) pode constituir uma área conceitual, um segmento desse estoque. As crianças irão entrar e sair desse segmento, mas este ainda permanece. 0 segmento pode se sobrepor a outro, refletir em outros, mas há uma ordem básica de crenças, valores e ideias (Hardman, 2001, p. 504).
}

Embora a criança se sobreponha, por exemplo, imitando ou incluindo pontos de vista adultos, no nível do comportamento, valores, símbolos, jogos, crenças e tradições orais, tem que haver uma dimensão exclusiva para a criança. 
Hardman cita Durkheim e Gombrich e considera o pensamento da criança do ponto de vista antropológico; e cita Vygotsky, Piaget e Isaacs considerando o ponto de vista psicológico. Ligando Piaget a Lévi-Strauss, Hardman comenta que pode haver alguns aspectos de pensamento mítico próximos ao pensamento da criança: "mentalidade simbólica".

Hardman conclui que:

- as crianças têm um mundo autônomo, independente, em certa medida, do mundo dos adultos;

- o pensamento e comportamento social das crianças não seria de todo incompreensível para os adultos.

Observações de Hardman:

- o ambiente do playground pode ser visto como um sistema de significados que revela uma estrutura em grande escala. Os objetos do ambiente são incorporados no jogo, não pelo que são neles, mas pelo significado a eles atribuídos: os objetos têm que qualificar (Gombrich);

- os contextos que definem os significados do ambiente são as situações imaginárias combinadas pelo grupo: algumas situações são brincadas com tanta frequência que as crianças conhecem certas regras para as quais o comportamento adere;

- as falas das crianças podem ser tomadas como partes e analisadas também em relação com outras falas ou ditados familiares. Por meio desse tipo de análise, um número considerável de valores das crianças pode ser levantado. Conceitos que têm valor na esfera do adulto começam a adquirir um valor para as crianças;

- podemos começar a compreender as crianças observando- as e escutando-as e, depois, interpretando o material coletado com vários métodos diferentes. Aqui começa, talvez, uma Antropologia das crianças, que pode ser estendida para:

1. a elaboração da ideia de um sistema semântico que não só depende do discurso, mas do ambiente biofísico; 
2. a construção de algum tipo de eixo de noções analíticas de formas de pensar aplicáveis às crianças (ex.: pensamento mágico e outros compilados por Piaget, Vygotsky, Saussure);

3. a análise das falas das crianças;

4. o exame das tradições orais, seus jogos e suas atividades de recreio e os valores por trás deles;

5. a análise de desenhos infantis.

Paralelamente aos primórdios da Antropologia da Infância, começa também um movimento na área da Sociologia. 0 francês Émile Durkheim (1922-1975) desenvolve estudos sobre socialização infantil, tendo como pano de fundo a necessidade de integração social do indivíduo. Embora tenha sido criticado também com relação aos conceitos similares ao esquema de desenvolvimento "etapista", de Piaget, interessa a introdução da ideia de que na sociedade infantil é importante observar o desenvolvimento social, em vez do biológico. Talcott Parsons (1951) continua com esta ideia, dizendo que a educação também era importante para eliminar possíveis desvios de integração do indivíduo no grupo.

Em 1982, o sociólogo Chris Jenks sistematiza as ideias acima e aponta que as crianças devem ser consideradas como "seres que têm as potencialidades para serem postos em contato com os seres humanos".

Norman Denzin propõe em Socialization of Childhood (1977) a necessidade de construir uma teoria nova que dê conta das questões que emergem das várias infâncias existentes no mundo.

Alguns marcos históricos no estudo sobre a infância:

- Anos 1970: 1979 foi instituído como o Ano Internacional da Criança, pelas Nações Unidas, que desenvolveram uma série de estudos sobre a situação mundial da infância que iriam provocar grande impacto na opinião pública, a respeito dos bolsões de pobreza das grandes cidades e de algumas áreas rurais europeias;

- Década de 1980: Criação e consolidação de ONGs voltadas para a proteção da Infância (Terre des Hommes, Save the Children, World Vision, entre outras), as maiores responsáveis pela reunião de dados significativos sobre a 
Infância. Os cientistas sociais têm pouca participação e há pouco diálogo entre o universo científico e os movimentos militantes, até hoje. Começam a surgir trabalhos científicos importantes, por exemplo: em 1982, na London School of Economics acontece um seminário sobre o tema das crianças adquirirem a cultura dentro da qual são socializadas. Participaram deste seminário antropólogos, sociólogos, psicólogos e historiadores e um dos resultados foi uma bibliografia selecionada por Christina Toren sobre estudos sobre a etnografia da infância (1988). Entre 1989 e 1994 é desenvolvida a pesquisa europeia Childhood as a cocial phenomen, desenvolvida em 19 países sob a coordenação de Jens Qvortrup, inaugurando um espaço de investigação científica sobre a Infância, espaço vital para as crianças e para a reflexão que se faz nas ciências sociais e na educação.

Até o fim dos anos 1990 surgem importantes centros de investigação:

- Centre for the Social study of childhood - University of Hull, na Inglaterra;

- Center for Child Focused Anthropological Research University of Brunel, na Inglaterra;

- Norwegian Center for Child Research - Universidade de Ciência e Tecnologia da Noruega, que edita a revista Childhood: a global journal on Child Research;

- Centro de Documentação e Informações sobre a Criança - Universidade de Minho, em Portugal;

- Center for Research on Childhood and Adolescence Universidade de Bielefeld, na Alemanha;

- Centro de Estudos sobre a Infância - Universidade Santa Úrsula, no Brasil. Abrem-se novas disciplinas nos cursos universitários, seminários e linhas de pesquisa.

- Commission on Anthropology of Children, Youth and Childhood - University of Sambalpur, na Índia, criada no âmbito do International Union of Anthropological and Ethnological Sciences (IUAES) que desenvolveu, em 2003, o XV International Congress. 


\section{Temas de discussão}

Direitos das crianças, abuso sexual, violência e tráfico, condutas sociais e políticas da infância e juventude, uso do espaço, modelos de investigação sobre e com crianças são alguns dos temas que aparecem nas discussões e reflexões da área de antropologia. Apesar do surgimento destes movimentos, ainda há relutância no seio da Antropologia. Não há um reconhecimento concreto da importância da contribuição dos estudos sobre a Infância para o conhecimento sobre as sociedades.

No Brasil, nos anos 1940, seguem-se as tendências verificadas na Europa e nos EUA: Roger Bastide aponta, na obra de Florestan Fernandes (1946) As trocinhas do Bom Retiro, a dificuldade de comunicação entre o mundo dos adultos e o das crianças.

Foram a exploração do trabalho infantil e a delinquência juvenil que, nos anos 1970, mobilizam as atenções; é encomendada pelo Tribunal de Justiça de São Paulo uma pesquisa desenvolvida pelo Cebrap (1973) - A criança, o adolescente e a cidade que, junto com outra no Rio de Janeiro, marcam o primeiro envolvimento das ciências sociais com as questões relativas à infância.

Hoje, nos primórdios do Século XXI, categorias como "menor abandonado" e "meninos de rua" são por todos conhecidas, o que tem gerado denúncias, reportagens e debates. Assim, surgem inúmeras teses na área de Psicologia, Educação e Assistência Social.

Na Revista Brasileira de Estudos Pedagógicos (1979), no Ano Internacional da Criança, há vários textos sobre a infância, como o de Alvim e Valadares, que, em 1988, fizeram um levantamento bibliográfico significativo sobre a criança no Brasil.

Apontado o "estado da arte", é necessário sair da discussão crítica, torná-la propositiva e melhorar a qualidade para construir uma nova epistemologia sobre a Infância.

Os britânicos Allison James (antropólogo) e Alan Prout (sociólogo) reúnem, em 1990, o material resultante das décadas anteriores e constroem uma proposta metodológica e teórica de investigação, identificando a emergência de um novo paradigma para o estudo social da Infância. Apontam que ele existe como potencial e que seus fundamentos são essenciais para uma nova fase de investigações sobre a Infância. Delimitam seis princípios base desse paradigma: 
1. a Infância, entendida como uma construção social, não é característica natural nem universal dos grupos humanos, mas um componente específico estrutural e cultural de várias sociedades;

2. a Infância deve ser considerada como variável de análise social: há uma variedade de infâncias;

3. as relações sociais e a cultura das crianças merecem estudos em si mesmas;

4. as crianças devem ser vistas como ativas na construção e determinação da sua própria vida social;

5. a etnografia é um método útil ao estudo da Infância: permite à criança participar e lhe dá voz direta na produção de dados sociais mais do que através de outras pesquisas;

6. a proclamação do novo paradigma da Sociologia da Infância deve também incluir e responder ao processo de reconstrução da Infância na sociedade.

Estes pontos tiveram grande impacto para as investigações antropológicas e sociais sobre a Infância. Mas uma das problemáticas que continua a persistir é "como trazer a relação entre o processo biológico e o social?"

0 conceito de socialização é, teoricamente, crucial, em torno do qual se renovaram alguns interesses antropológicos, como, por exemplo, com relação a sociedades não ocidentais e de tradição oral.

Em 1998, seguindo as reflexões acima elencadas, Christina Toren (Inglaterra) afirmava que a teoria de Piaget era mais do que a sistematização de estágios. A importância da contribuição desta pesquisadora está na construção de uma nova epistemologia sobre a Infância por juntar os saberes e práticas da Psicologia com a Antropologia.

Toren criou um centro de investigação sobre a Infância na Brunel University, em Londres, chamado Child-focused Anthropology. A abordagem não é multiplicar etnografias sobre a infância de uma dada sociedade: estas devem ser parte dos estudos sobre a sociedade, caso contrário os estudos das mesmas ficariam incompletos. 
Em 2002, Clarice Cohn apresenta alguns exemplos, reforçando a ideia de que há, na infância, um processo de produção cultural e de reprodução cultural. Ela aponta uma revisão do conceito de cultura (2005, p. 19-20) pelos antropólogos: não são valores ou crenças que são os dados culturais, mas a lógica que os conforma - um sistema simbólico acionado pelos atores sociais a cada momento para dar sentido às suas experiências; aquilo que faz com que as pessoas possam viver em sociedade, compartilhando sentidos formados a partir de um mesmo sistema simbólico ("Valores" como palavras de uma frase, "Cultura" como sistema linguístico que permite articular palavras, frases, ideias). A cultura está sempre em transformação e mudança. 0 contexto cultural é esse sistema simbólico, imprescindível para entender o lugar da criança: é estruturado e consistente.

Os indivíduos da sociedade passam a ser vistos como atores sociais, recriando a sociedade a todo momento. Esses conceitos- chave da antropologia permitem ver a criança de uma forma totalmente nova, como tendo um papel ativo na definição da sua própria condição.

Clarice Cohn defende uma antropologia da criança e não da Infância, entendendo esta como um modo particular, não universal, de pensar a criança: é, segundo Ariès, uma construção social e histórica do Ocidente que ele chamou de "sentimento da infância". Em cada sociedade a ideia de Infância é definida de formas diferentes e uma antropologia da criança deve ser capaz de apreender essas diferenças. A análise antropológica deve abranger outros campos para entender o que significa ser criança nesses contextos (por exemplo, as concepções particulares de "ser humano"). "Crianças existem em toda parte e podemos estudá-las comparando suas vivências: mas as mesmas são diferentes para cada lugar e, por isso, devem ser compreendidas no seu contexto sociocultural" (Cohn, 2005, p. 19).

As crianças não só herdam uma posição, mas também atuam, criando relações:

- criança como "ator social";

- criança como "produtora de cultura" (não só produzidas pelas culturas).

A questão é: como a criança formula um sentido sobre o mundo ao seu redor? A criança não sabe menos que o adulto, sabe outra coisa. A antropologia da criança dialoga com as análises de 
desenvolvimento cognitivo. A Antropologia da criança quer saber a partir de que sistema simbólico a criança elabora sentidos $e$ significados.

Falar em uma cultura infantil é universalizar, negando particularidades socioculturais.

Falar em culturas infantis é mais adequado. Mas temos que ter o cuidado de compreender que elas podem não ser exclusivas do universo infantil: por exemplo, as brincadeiras infantis não constituem uma área cultural exclusivamente ocupada pelas crianças. Para entender o que elas fazem nessas brincadeiras é necessário compreender sua simbologia (que extrapola o mundo das crianças).

\section{Definição da condição social da criança}

É importante observar, em contexto, concepções, meios e processos. Devem constituir objetos de pesquisa social das culturas infantis:

- suas vivências;

- suas representações;

- seus modos próprios de ação e de expressão.

Ian Butler (1996) diz que o conhecimento sobre crianças é o que os adultos sabem, não o que as crianças têm a dizer. José Martins (1993) afirma que as crianças são as maiores portadoras de crítica social. Irene Rizzini (2002) defende a participação e o protagonismo das crianças na elaboração e execução de programas de ação social. Iturra (1996) diz que os adultos não valorizam o que as crianças sentem e que cada sociedade é multicultural. Há três culturas: a infantil, a adulta e a erudita. A infância precisa ser estudada de acordo com as características mutáveis do contexto em que vive.

A criança adota e absorve a realidade dos adultos à sua volta e vai, ao mesmo tempo, recriando-a e construindo seu próprio universo simbólico, que só ela entende. Mas todo adulto que já foi criança também viveu de acordo com essa realidade da qual ele se distancia. Iturra distingue:

- o processo de aprendizagem que é inerente à descoberta, à invenção, à troca, à representação e recriação da realidade; 
- o processo de ensino que regulamenta a vida das crianças no que está além do seu cotidiano, introduzindo, por meio da escola um conhecimento universal.

0 autor considera a educação (processo social) e a escola (local principal do processo educacional) como figuras centrais para o estudo da Infância. Do meu ponto de vista, acredito também, e muito fundamentalmente, em todos os processos educacionais que acontecem fora da educação formal, em que expressões espontâneas das crianças têm lugar, e, onde, por excelência, são construídas as culturas infantis.

Iturra (2000) define "epistemologia infantil" como o conhecimento ativo e criador da criança, o que ela sabe do mundo em que vive, dos que a rodeiam e de si mesma. Esta é uma definição nova na Antropologia sobre a Infância, que estimula um interessante debate sobre a origem e a construção do desenvolvimento infantil.

Pinto e Sarmento (1997) perguntam-se sobre a natureza da produção das culturas infantis, assumindo sua pluralidade. Reabre-se a discussão particular/universal (fundadora da ciência antropológica), no centro da qual estão os diferentes modos como a Infância, enquanto construção social, manifesta unicidade. Há uma mudança de atitude ética e metodológica em curso: a partir de das crianças para o estudo das realidades da infância. Os cientistas que continuam a falar em nome de crianças têm tido grande dificuldade nesse sentido, mesmo que pensem de modo contrário (a questão da alteridade). As crianças continuam a ocupar um lugar marginal nas ciências sociais.

Reforço, aqui, a necessidade de que as crianças falem, se manifestem e se expressem por si mesmas.

James, Jenks e Prout (1990) colocam quatro princípios vertentes de investigação antropológica sobre a Infância:

1. a Infância considerada como construção social: defende sua pluralidade e diversidade - liberta a criança do "determinismo biológico";

2. o mundo social da Infância é considerado como um mundo à parte, cheio de significados próprios e não um precursor do mundo adulto. A Infância socialmente estruturada, não familiar para os adultos, é passível de ser revelada pela pesquisa etnográfica; 
3. as crianças são consideradas um grupo minoritário, "um outro silenciado" e pretende-se dar-lhe voz, sugerindo pesquisas que se façam para as crianças e não só sobre crianças;

4. a infância é entendida como categoria socioestrutural, com características universais: sua manifestação varia de uma sociedade para outra, mas é uniforme dentro da mesma sociedade.

Além das abordagens acima apresentadas, os estudos sobre a Infância também fazem parte de uma série de debates antropológicos atuais:

- agência - estrutura;

- universalidade - particularidade;

- globalidade - localidade;

- continuidade - mudança;

- eu - outro.

Hirschfeld (2002) aponta que o pressuposto da antropologia do processo realizado pelas crianças, melhor do que por quaisquer outros, é o da aquisição cultural do conhecimento: as crianças formam subculturas "semiautônomas".

Como principais referências, no Brasil, da área da Antropologia da Infância, podemos citar Florestan Fernandes, Aracy Lopes da Silva, Ângela Nunes e Clarice Cohn. Florestan Fernandes, cuja obra de referência sobre seus estudos relacionados à Infância encontra-se em "As Trocinhas do Bom Retiro" (1944-1947), defendia o registro dos elementos constitutivos das culturas infantis a partir de observações sobre grupos de crianças dos bairros operários de São Paulo que brincavam na rua. Ele entendia a criança como participante ativo da vida social - o autor observou, registrou e analisou como se dava o processo de socialização de crianças e como se constituíam as culturas infantis.

Florestan Fernandes afirma que, por meio do estudo dos folguedos infantis, os grupos infantis apresentam-se como grupos de iniciação à vida adulta (Friedmann, 2006).

Roger Bastide prefaciou essa obra, ressaltando a importância do estudo do folclore infantil, enfatizando a dificuldade de 
comunicação entre o mundo dos adultos e o das crianças. Ele defendia a multiplicação das pesquisas nessa área e a importância de estudar as "representações infantis, conhecer mais sobre o mundo de brinquedos, brincadeiras e jogos". Ele afirma que: "Para poder estudar a criança é preciso tornar-se criança"; não adianta só observar a criança, "é preciso penetrar além do círculo mágico que dela nos separa, em suas preocupações, suas paixões, é preciso viver o brinquedo" (1979).

Aracy Lopes da Silva (2002), que desenvolveu pesquisas com crianças indígenas, propõe a criação de uma Antropologia da criança ou da Infância para desvelar uma dimensão da realidade social a partir de pesquisas etnológicas. Ela propõe "que se escute o que ela tem a dizer, que se veja o que ela faz, que se seja sensível ao que ela sente, que se acolha o que ela expressa" (p. 240).

Ângela Nunes (2003) aponta o trajeto da Antropologia da Infância, conforme descrito neste artigo; ela desenvolveu pesquisas junto a comunidades indígenas. Atualmente desenvolve na Europa pesquisas junto a crianças migrantes.

Clarice Cohn (2005) contribui com suas reflexões teóricas, apontando possíveis diálogos das pesquisas antropológicas:

- com a Psicanálise, a Psicologia, a Pedagogia e as ciências da educação: na escola, as crianças, consideradas como atores sociais, criam sentidos e atuam sobre o que vivem. A Antropologia contribui com "análises" do que as crianças estão fazendo, do sentido que elaboram, das atividades que desenvolvem, das relações que estabelecem e das suas aprendizagens. A criança é considerada produtora, além de receptora de cultura;

- com a história da infância: é possível, por meio de textos sobre crianças, nas artes plásticas e nos tratados de educação e Pedagogia, observar as mudanças das concepções de Infância no tempo. A Antropologia voltada para o passado é importante no debate das imagens sobre crianças e sua atuação no mundo;

- com as ciências jurídicas: para compreender o Estatuto da Criança e do Adolescente (ECA), há necessidade de compreender as concepções de criança e de infância que o embasam;

- com formulação de políticas públicas, embora seja uma área polêmica. 


\section{Metodologias}

A Antropologia foi criando, propondo e utilizando algumas formas de pesquisa muito particulares desta ciência:

- observação participante: interação direta e contínua do pesquisador com as crianças;

- coleta de desenhos e histórias elaboradas pelas crianças;

- registros audiovisuais.

A Antropologia das crianças pode ser feita:

- com as crianças como sujeitos;

- com os profissionais falando sobre as crianças e sobre eles.

A pesquisa pode ser feita a partir da:

- observação participante;

- interlocução direta com as crianças;

- recordação de memórias de infância de adultos;

- recordação da imagem de infância criada pelos adultos.

Fontes ricas sobre o que é ser criança e suas ações no mundo são a literatura, o cinema, textos jurídicos, documentos de ONGs.

Para um estudo sobre crianças ser antropológico, não é necessário que seja apenas sobre crianças de outras culturas e sociedades: pode ser sobre fenômenos e temas próximos do próprio meio social do pesquisador, evitando a ilusão do conhecimento prévio. Ele deve ser capaz de reaprender o que the parece natural. Como afirma Cohn, tanto mais devemos desconfiar do que vemos e ouvimos, quanto mais óbvio nos parecer. E ainda ela afirma que não há imagem produzida sobre crianças e infâncias, ou pelas crianças, que não seja produto de um contexto sociocultural e histórico específico. 


\section{Outros autores relevantes na área da Antropologia da Infância}

- Gregory Bateson: importante antropólogo que desenvolveu pesquisas junto com Margaret Mead.

- Helen B. Schwartzman (2001): antropóloga americana que reúne na sua obra Children and Anthropology: Perspectives for the $21^{\text {st }}$ century, com contribuições de antropólogos australianos, americanos, canadenses e ingleses.

- Jean Pierre Rossie ("Toys, Play, Culture and Society", 2005): antropólogo belga que desenvolve pesquisas no Sahara e sobre as culturas da África do Norte.

- Alberto del Castillo Troncoso ("Conceptos, imágenes y representaciones de la niñez en la ciudad de México" 1880-1920): antropólogo mexicano que trabalhou a partir de fotografias.

- William Corsaro ("Sociology of Childhood", 2005): americano que defende estudos com e não sobre crianças. Ele trabalha com pesquisa etnográfica comparativa.

- Régine Sirota (França): importante socióloga contemporânea pesquisa etnográfica sobre os aniversários na infância como ritual.

- Jens Qvortrup (Dinamarca): PhD, professor de sociologia da Universidade de Copenhagen, com estudos voltados para a sociologia da infância, geracional, pesquisas e sociologia comparada. Foi um dos primeiros a engajar-se na área da Sociologia da Infância. Dirigiu o estudo pioneiro Childhood como um fenômeno social (Childhood as a Social Phenomenon), entre 1987 e 1992 e é autor de diversos livros na área.

- Renata Meirelles (2006): defende tese sobre "Antropologia do imaginário das brincadeiras das crianças das comunidades ribeirinhas".

\section{Cultura}

- Walter Benjamin (Antropologia Filosófica): Teoria crítica da cultura e da modernidade que contribui com uma perspectiva interdisciplinar ao considerar singularidade 
e totalidade, reconhecendo valores, afetos, desejos e paixões das crianças como fundamentais. A criança passa a ser considerada como fruto da tradição cultural, capaz de recriá-la (arte, cinema e literatura, revelando o próprio olhar da criança, ouvindo-as). Infância considerada como um coletivo, chave para a compreensão de uma época.

\section{Ética}

- Sonia Kramer: pesquisadora brasileira que traz importantes reflexões a respeito da ética nas pesquisas com crianças.

\section{Biologia}

- Jerôme Kagan: As influências biológicas mais importantes vêm da maturação das estruturas do sistema nervoso central durante os doze primeiros anos de vida. A experiência é tão importante quanto a biologia.

- Boris Cyrulnik: Médico francês, etologista, psiquiatra e neurologista, é conhecido por ter desenvolvido o conceito de "resiliência psicológica", entre outros.

\section{Linguagem}

- Lev Vygotsky: Psicólogo russo que defendeu que o desenvolvimento das crianças acontece a partir das interações sociais. Morreu prematuramente. Seu pensamento dialogou com o pensamento marxista.

- Solange Jobim e Souza: Doutora em Educação, que traz uma importante contribuição para a influência da cultura e da linguagem na infância.

\section{Pesquisas}

É importante destacar os inúmeros pesquisadores, publicações e reflexões, centros de pesquisa, cursos, seminários e sites de referência surgidos nos últimos dez anos. As pesquisas e os resultados obtidos têm dialogado com os trabalhos práticos que vêm sendo desenvolvidos, sobretudo, junto a crianças e jovens nos seus cotidianos, nas instituições formais - escolas - e não formais - ruas, ONGs, clubes etc. em diversas culturas e países do mundo. 
Muitas reflexões têm sido fruto dessas pesquisas, sobretudo sobre questões éticas, o lugar das crianças nesse contexto, os direitos e vozes infantis, os desafios com relação à escuta, registro e observação de crianças.

Não restam dúvidas da transcendência que as ciências sociais têm assumido, de forma crescente, na possibilidade de olhar para estes atores - crianças e jovens - com suas autorias, suas culturas e linguagens e o potencial destes estudos para possibilitar diálogos interdisciplinares e propostas intersetoriais. Vislumbra-se o desafio de perpassar fronteiras teóricas e olhar para as crianças de forma integral e integrada, dentro e fora dos contextos escolares e familiares.

\section{Uma proposta de interlocução entre Educação e Antropologia}

Na tese de doutorado Paisagens Infantis: uma incursão pelas naturezas, linguagens e culturas das crianças, de minha autoria, trago para reflexão a importância, tanto para o âmbito educacional quanto para as ciências sociais, de se estabelecer um diálogo entre as duas áreas, desafiando educadores a se posicionarem como observadores-pesquisadores-antropólogos, em prol de um conhecimento mais profundo de necessidades, interesses e habilidades das crianças nos diversos contextos de atuação. Constitui, ao mesmo tempo, um grande desafio, os antropólogos incorporarem e reconhecerem a antropologia das crianças enquanto um campo fértil de pesquisas e contribuições na área.

\section{REFERÊNCIAS}

ALVIM, M. R. B.; VALLADARES, L. do P. Infância e sociedade no Brasil: uma análise da literatura, Boletim bibliográfico e informativo de Ciências Sociais, Rio de Janeiro, n. 26, p. 3-43, ago. 1988.

ARIÈS, P. L'enfant et la vie familiale sous l'Ancien Régime. Paris: Plon, Point Seuil, 1960.

BASTIDE, R. Nota explicativa. In: FERNANDES, F. Folclore e mudança social na cidade de São Paulo. 3. ed. São Paulo: Martins Fontes, 2004 (p. 229-231). 
BATESON, G. Rumo a uma epistemologia da comunicação, Ciberlegenda, n. 5, 2001.

BENEDICT, R. The chrysanthemum and the sword. Boston/ Massachusetts: Houghton/Mifflin, 1946.

BENJAMIN, W. Reflexões: a criança, o brinquedo, a educação. São Paulo: Summus, 1984.

. Charles Baudelaire: um lírico no auge do capitalismo. São Paulo: Brasiliense, 1989. v. 3. (Col. Obras Escolhidas).

Rua de sentido único e infância em Berlin por volta de 1900. Lisboa: Relógio D’Água, 1992. (Col. Obras Escolhidas).

- Sobre Arte, Técnica, Linguagem e Política. Lisboa: Relógio D’Água, 1992. (Col. Obras Escolhidas).

CEBRAP. A criança, o adolescente e a cidade. São Paulo: Relatório de Pesquisa, 1972.

COHN, C. Antropologia da criança. Rio de Janeiro: Jorge Zahar, 2005.

CORSARO, W. A. The Sociology of Childhood. California: Pine Forge Press, 1997.

CYRULNIK, B.; MORIN, E. Diálogo sobre a natureza humana. Lisboa: Instituto Piaget, 2004.

DURKHEIM, É. Sociologia, educação e moral. Portugal: Réseditora, 1984.

FERNANDES, F. Folclore e mudança social na cidade de São Paulo. 2. ed. Petrópolis: Vozes, 1979.

FRIEDMANN, A. O brincar no cotidiano da criança. São Paulo: Moderna, 2006.

Paisagens infantis: uma incursão pelas naturezas, linguagens e culturas das crianças. São Paulo: Faculdade de Ciências Sociais da PUC, Tese de Doutorado em Antropologia, 2011. 
- O desenvolvimento da criança através do brincar.

São Paulo: Moderna, 2006.

Antropologia da Infância. São Paulo: Isevec, 2009.

HARDMAN, C. Can there be an Anthropology of Children?

Childhood. In: London: Sage Publications, 2011. v. 8. n. 50.

p. $95-99$.

ITURRA, R. O saber sexual das crianças. Desejo-te porque te amo. Porto: Edições Afrontamento, 2000.

JAMES, A.; PROUT, A. (Orgs.). Constructing and reconstructing childhood: contemporary issues in the sociological study of childhood. London: The Palmer Press, 1990.

JAMES, A.; JENKS, C.; PROUT, A. (Orgs.). Theorizing Childhood. London: Plity, 2002.

JAVEAU, C. Criança, infância(s), crianças: que objetivo dar a uma ciência social da infância? In: Revista Educação e Sociedade. Campinas, 2005. v. 26, n. 91, p. 379-389.

JENKS, C. The sociology of childhood: Essential readings. Hampshire: Gregg. Revivals (Great Britain an USA), 1982.

JOBIM e SOUZA, S. (Org.). Subjetividade em questão: a infância como crítica da cultura. Rio de Janeiro: 7 Letras, 2000.

Kramer, S.; Leite, M. I. Infância: fios e desafios da pesquisa. Campinas / São Paulo: Papirus, 1996.

LÉVI-STRAUSS, C. Mythologiques IV: L'Homme nu. Paris: Plon, Point Seuil, 1971.

LÉVI-STRAUSS, C. O cru e o cozido. São Paulo: Cosac Naify 2004.

Letras, 1997. Olhar, escutar, ler. São Paulo: Companhia das

LOPES DA SILVA, A.; NUNES, A.; MACEDO, A. V. Crianças indígenas: ensaios antropológicos. São Paulo: Global, 2002. 
MEAD, M. Adolescencia y Cultura en Samoa. Barcelona: Paidós, 1971.

MEIRELLES, R. Águas infantis: um encontro com brinquedos e brincadeiras da Amazônia. Dissertação de Mestrado. São Paulo: Faculdade de Educação da Universidade de São Paulo, dissertação de mestrado em Educação, 2007.

NUNES, A. Brincando de ser criança: contribuições da etnologia indígena brasileira à antropologia da infância. Lisboa (Portugal): ISCTE, Tese de doutorado em Antropología, 2003.

MOURITSEN, F.; QVORTRUP, J. Childhood and Children's Culture. University Press of Southern Denmark, 2002.

OPIE, I.; OPIE, P. Children's games in street and playground. New York: Oxford, 1984.

PIAGET, J. A formação do símbolo na criança - imitação, jogo e sonho, imagem e representação. Rio de Janeiro: Zahar, 1978.

PINTO, M.; SARMENTO, M. J. (Orgs.). As crianças: Contextos e Identidades. Braga: Centro de Estudos da Criança, Universidade do Minho, 1997.

POSTMAN, N. O desaparecimento da Infância. Rio de Janeiro: Graphia, 1999.

PROUT, A. Reconsiderar a Nova Sociologia da Infância. Braga: Universidade do Minho, 2004.

RIZZINI, I. Assistência à infância no Brasil: uma análise de sua construção. Rio de Janeiro: Editora Universitária Santa Úrsula,1993.

ROSSIE, J. P. Toys, play, culture and society: an anthropological approach with reference to North Africa and the Sahara.

Stockholm: Sitrec, 2005

SARMENTO, M. J.; CERISARA, A. B. Crianças e miúdos: perspectivas sociopedagógicas da infância e educação. Porto: Asas, 2004.

SARMENTO, M. J. O Estudo de caso etnográfico em Educação. Braga: Instituto de Estudos da Criança / Portugal: Universidade do Minho, 2003. 
SIROTA, R. Emergência de uma Sociologia da Infância: evolução do objeto e do olhar. Cadernos de Pesquisa. Fundação Carlos Chagas, n. 112, mar. de 2001, p. 7-31.

SCHWARTZMAN, H. B. Transformations: The Anthropology of children's play. New York: Plenum Press, 1978.

TOREN, C. Making sense of hierarchy: Cognition as social process in Fiji. London: Athlone Press, 1990.

Mind, materiality and history: Explorations in Fijian ethnography, London/New York: Routledge, 1999.

VASCONCELLOS, V. M. R. de; SARMENTO, M. J. Infância (in) visível. Araraquara: Junqueira\&Marin, 2007.

VYGOTSKY, L. Pensamento e Linguagem. Lisboa: Antídoto, 1979.

Play and its role in the Mental Development of the Child, Psychology and Marxism Internet Archive (marxists.org), 2002 (publicado originalmente em 1933). Disponível em: <http://www.marxists.org/archive/vygotsky/ works/1933/play.htm>. Acesso em: 3 nov. 2011. 